\title{
3C-SiC Heteroepitaxy on Hexagonal SiC Substrates
}

Anne Henry, Xun Li, Henrik Jacobson, Sven Andersson, Alexandre Boulle, Didier Chaussende and Erik Janzén

\section{Linköping University Post Print}

N.B.: When citing this work, cite the original article.

Original Publication:

Anne Henry, Xun Li, Henrik Jacobson, Sven Andersson, Alexandre Boulle, Didier Chaussende and Erik Janzén, 3C-SiC Heteroepitaxy on Hexagonal SiC Substrates, 2013, Materials Science Forum, (740-742), 257-262.

http://dx.doi.org/10.4028/www.scientific.net/MSF.740-742.257

Copyright: Trans Tech Publications http://www.ttp.net/

Postprint available at: Linköping University Electronic Press http://urn.kb.se/resolve?urn=urn:nbn:se:liu:diva-96508 


\title{
3C-SiC heteroepitaxy on hexagonal SiC substrates
}

\author{
Anne Henry ${ }^{1, a}$, Xun $\mathrm{Li}^{1, \mathrm{~b}}$, Henrik Jacobson ${ }^{1, \mathrm{c}}$, Sven Andersson ${ }^{1, \mathrm{~d}}$, Alexandre Boulle ${ }^{2, \mathrm{e}}$, \\ Didier Chaussende ${ }^{3, f}$ and Erik Janzén ${ }^{1,9}$, \\ ${ }^{1}$ Department of Physics, Chemistry and Biology, Linköping University, 58183 Linköping, Sweden \\ ${ }^{2}$ Science des Procédés Céramiques et de Traitements de Surface, CNRS UMR 7315, \\ Centre Européen de la Céramique, 12, rue Atlantis, 87068 Limoges Cedex, France \\ ${ }^{3}$ LMGP, CNRS UMR 5628, Grenoble INP, 3 parvis Louis Neel, BP257, 38016 Grenoble, France \\ a anhen@ifm.liu.se, ${ }^{b} x u n l i @ i f m . l i u . s e,{ }^{c}$ henrik.jacobson@liu.se, ${ }^{d}$ svean@ifm.liu.se, \\ ealexandre.boulle@unilim.fr, ${ }^{\mathrm{f}}$ didier.chaussende@grenoble-inp.fr, ${ }^{9}$ erija@ifm.liu.se
}

Keywords: 3C-SiC(111), heteroepitaxy, CVD, XRD, Photoluminescence

\begin{abstract}
The growth of 3C-SiC on hexagonal polytype is addressed and a brief review is given for various growth techniques. The Chemical Vapor Deposition is shown as a suitable technique to grow single domain 3C epilayers on $4 \mathrm{H}-\mathrm{SiC}$ substrate and a $12.5 \mu \mathrm{m}$ thick layer is demonstrated; even thicker layers have been obtained. Various characterization techniques including optical microscopy, X-ray techniques and photoluminescence are compared for the evaluation of the crystal quality and purity of the layers.
\end{abstract}

\section{Introduction}

Epitaxy of the 3C-SiC polytype has been thoroughly investigated because it can easily be achieved on inexpensive silicon substrates. This interest has also been driven due to its remarkable electrical and mechanical properties and many applications can be envisaged. One of the first is due to the hardness of the material — useful for MEMS [1] —, followed by fast-switching, high-power electronic devices as MOSFET due to the high channel mobility observed in 3C-SiC [2]. More recently both bio- and hemocompatibility of 3C-SiC have open more doors as biomedical applications with sensors or smart biomedical implants [3]. However, as $3 \mathrm{C}$ bulk material is still not commercially available, heteroepitaxy is needed. Until now silicon has been mainly used as substrate with the drawback of getting high density of defects. Besides the internal stress in the 3C material there are inversion domain boundaries (IDB), microtwins (MT) and stacking faults (SF). Attempts to reduce these defects with undulant-Si substrates or patterned substrates have been proposed [4], however due to lattice mismatch with the substrate and the strong difference in thermal expansion coefficients, stress is still expected to be present.

Therefore as alternative, hexagonal SiC substrates have been proposed using different growth techniques. In this case new electronic devices can be envisaged since due to abrupt changes in spontaneous polarization in the hexagonal SiC, two-dimensional electron or hole gas can be formed at the interface [5, 6]. Even if stress in the 3C layer is considerably reduced using hexagonal-SiC instead of Si as substrate, other defects such as double positioning boundaries (DPB) and SF are still present in the 3C material.

One of the first investigations was with chemical vapor deposition (CVD) as growth technique and using Si- and C-face Acheson grown 6H-SiC [7]; high densities of DPB and triangular defects were noted. Later reduction of DPB was observed only for thick 3C layer $(>30 \mu \mathrm{m})$ grown on $15 \mathrm{R}$, but not when using $6 \mathrm{H}$ as substrate; discussion regarding how to control the lateral growth from various facets of the crystal showed the role of the dangling bonds on the facets [8]. The effect of in-situ etching of the (0001) 6H-SiC surface prior the growth of DPB free 3C layer was reported and associated to the possibility to obtain a step flow growth mechanism [9]. Contrarily, another study revealed that only the growth conditions could affect the density of DPB and not the substrate surface preparation; a 3C layer grown at $1450{ }^{\circ} \mathrm{C}$ followed by another one grown at $1700{ }^{\circ} \mathrm{C}$ led to thick DPB-free layers[10]. Other growth techniques such as sublimation epitaxy [11] or vaporliquid-solid (VLS) [12] have also been investigated, in both cases inhomogeneity (inclusion of 


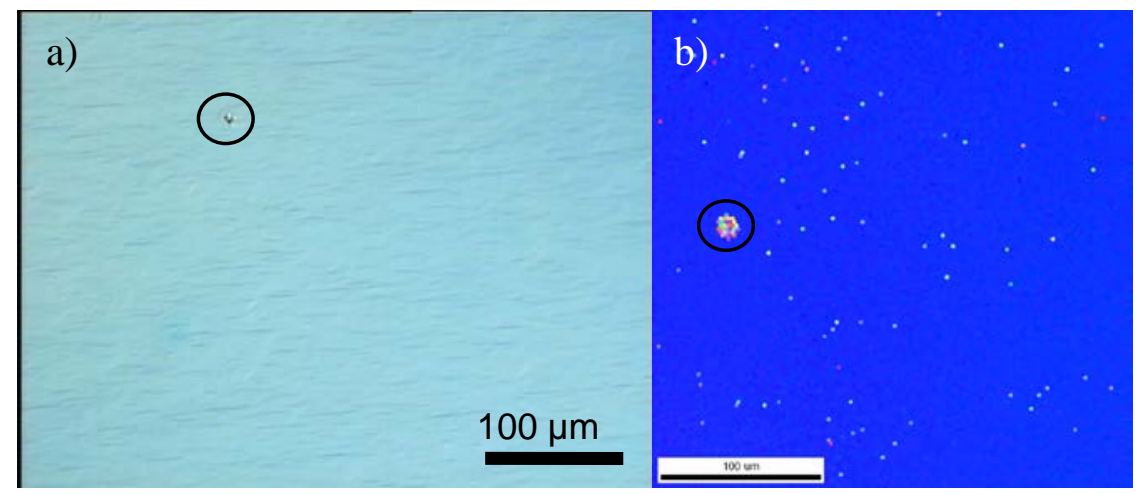

Fig. 1 : a) Nomarski image of a $12.5 \mu \mathrm{m}$ thick 3C-SiC epilayer grown on $4 \mathrm{H}(0001)$ SiC substrate and b) EBSD image of the same sample. The small dots are artifacts from the set-up except the large spot which could be related to defect similar than observed on the microscope image and which is underline by a circle on both images.

undesired polytype as replication from the substrate), DPB and SF were observed. With the latter technique (VLS) $1 \mathrm{~cm}^{2}$ DPB free layer could be achieved on $6 \mathrm{H}$ - and $4 \mathrm{H}$-SiC substrate; however reproducibility was difficult [12]. The nucleation of 3C on on-axis hexagonal polytype has also been addressed at high temperature and key points to get single domain were related to the initial step density of the substrate and the interaction between the steps and the anisotropic lateral growth of the 3C domains [13]. With top-seeded solution method, DPB free 3C layers were obtained using off-axis $6 \mathrm{H}$-SiC substrates, but towards [1-100] instead the standard [11-20] [14]. Molecular beam epitaxy using solid source evaporation is proposed to achieve the growth of heteropolytypic structures, however many challenges are still not resolved with this technique [15]. Very few simulation works have been published up to now; recently growth for high quality 3C layers on highly misoriented $6 \mathrm{H}$ was suggested to be more promising than the use of $4 \mathrm{H}-\mathrm{SiC}$ substrate. [16]

As can be seen from the review of the previous works heteroepitaxy of 3C-SiC on on-axis $4 \mathrm{H}$ substrate in combination with CVD technique has not been tested, to the best of our knowledge, except for patterned surface [17]. $4 \mathrm{H}-\mathrm{SiC}$ as substrate was supposed to be the most difficult challenge due to surface energy consideration and hexagonality. We started preliminary work using 4H as substrate with chloride based epitaxy and showed the possibility to get reliable layer and Schottky contact to perform electrical measurements [18]. More recently we used standard chemistry with silane and propane as precursors in a hot-wall CVD reactor [19].

\section{Experimental details}

A horizontal hot-wall CVD reactor has been used for the growth of 3C epilayers on hexagonal substrates. No rotation is applied to the substrates which have a size of about $2 \mathrm{x} 2 \mathrm{~cm}^{2}$. In this paper only results using the standard chemistry with silane and propane as precursors are reported. The precursors were carried by a massive flow of hydrogen mixing with a small flow of argon $\left(\mathrm{Ar} / \mathrm{H}_{2}=\right.$ $5 \%)$. No gas liner was used to direct the gas straight into the susceptor in laminar flow conditions, thus limiting the growth rate to typically $4-5 \mu \mathrm{m} / \mathrm{h}$. Growth is normally performed at a reduced pressure of 200 mbar, some test-growths were performed at higher pressures. Various growth parameters have been optimized; they include $\mathrm{C} / \mathrm{Si}, \mathrm{Si} / \mathrm{H}_{2}$, temperature and starting growth conditions. A small addition of $\mathrm{N}_{2}$ gas was generally used, since it was suggested to help to stabilize the 3C polytype, giving a net doping concentration in the low $10^{16} \mathrm{~cm}^{-3}$ range. The morphology of the epilayers was studied through an optical microscope with Nomarski differential interference contrast (NDIC). Surface roughness is measured by atomic force microscopy (AFM) in tapping mode and electron back scattering diffraction (EBSD) is used to control the presence of various domains or polytype mixing on the grown surface [20]. The thickness of the layers was determined either from a cleaved face of the sample or from reflectance technique. Low temperature photoluminescence (LTPL) was used to control the polytype of the epilayers. Results from X-ray 
techniques including high-resolution rocking curve, poles figures and reciprocal space maps are presented.

\section{Results}

By optimizing various growth parameters, such as conditions of temperature ramp-up, starting of the growth, growth temperature, $\mathrm{C} / \mathrm{Si}$ ratio, growth rate and $\mathrm{SiH}_{4}$ flow, we successfully grew 3C epilayers on $4 \mathrm{H}-\mathrm{SiC}$ free of DPB within the grown area $\left(2 \times 2 \mathrm{~cm}^{2}\right.$ in our case). Generally for the best results: the growth temperature was close to $1350{ }^{\circ} \mathrm{C}$ and the $\mathrm{C} / \mathrm{Si}=1$, although $\mathrm{C}$ rich conditions are needed during temperature ramp-up or before starting the growth. A typical Nomarski image recorded from a $12.5 \mu \mathrm{m}$ thick epilayer is shown in Fig.1.a. For this growth the run was starting by stabilizing the $\mathrm{H}_{2}$ (+Ar) flow through the cell. Temperature ramp-up was conducted to $1250{ }^{\circ} \mathrm{C}$ within $30 \mathrm{~min}$. A stabilization step of $10 \mathrm{~min}$ was done at this temperature before ramping up the temperature to $1350{ }^{\circ} \mathrm{C}$. Reaching this growth temperature propane was first introduced to the cell for $5 \mathrm{~min}$ and with the same flow as required for the growth. Then $\mathrm{N}_{2}$ and $\mathrm{SiH}_{4}$ were added to the gas mixture. The growth lasted for $3 \mathrm{~h}$ with $\mathrm{C} / \mathrm{Si}=1, \mathrm{Si} / \mathrm{H}_{2}=0.015 \%$ and $\mathrm{N} / \mathrm{C}=0.4 \%$. A rather smooth surface is seen (Fig.1.a) with a surface roughness of about $1 \mathrm{~nm}$ as measured with AFM on a 10x10 $\mu^{2}$ area. Few pits or particles, as indicated by the circle in Fig.1.a, were rarely observed. This morphology is typical for DPB-free layers; no mosaic pattern with boundaries is found. EBSD analyses conducted on this top surface reveal a uniform map: only one type of diffraction pattern was collected. This has been repeated on other locations of the layer. The confidence index has also been evaluated and found to be close to $100 \%$ except close to the particles. While Nomarski images only show the top surface, EBSD allows a slightly more deep investigation with a depth of few hundreds of nm. It is thus needed to apply technique(s) which could give information on more "bulky" part of the layer. High resolution transmission microscopy has been used in the literature [see ref. 21] however it needs heavy sample preparation and is thus destructive. X-Ray diffraction (XRD) which allows more bulk investigation can be used. After careful crystal alignment, we recorded a reciprocal space map (RSM) of the 113 reflection. An example is given in Fig.2.a for the same epilayer as Fig.1. Fig.2.b shows the RSM after rotating the sample with $60^{\circ}$ around its symmetry axis: almost no diffraction is detected. Rotating again the crystal with $60^{\circ}$ (thus total rotation of $120^{\circ}$ ) allows high detection of an equivalent direction. The percentage of the presence of a second domain can be evaluated from the intensity recorded and was found for this $12.5 \mu \mathrm{m}$ thick epilayer to be less than $0.1 \%$. However, we should point out that the penetration depth of the X-rays for the (113) reflection is $8 \mu \mathrm{m}$ (1/e attenuation criterion), whereas it is $22 \mu \mathrm{m}$ for the (111) reflection. Presence of DPB can also be evaluated with a RSM of the (111) Bragg peak which allows also the analysis of stacking faults (SF) in the layer. An example is given in Fig. 3 for the same sample as in Fig. 1 and 2. The streak denoted PSD is due to the experimental set-up (position sensitive detector). The streak with angle of $70^{\circ}$ is due to SFs lying in

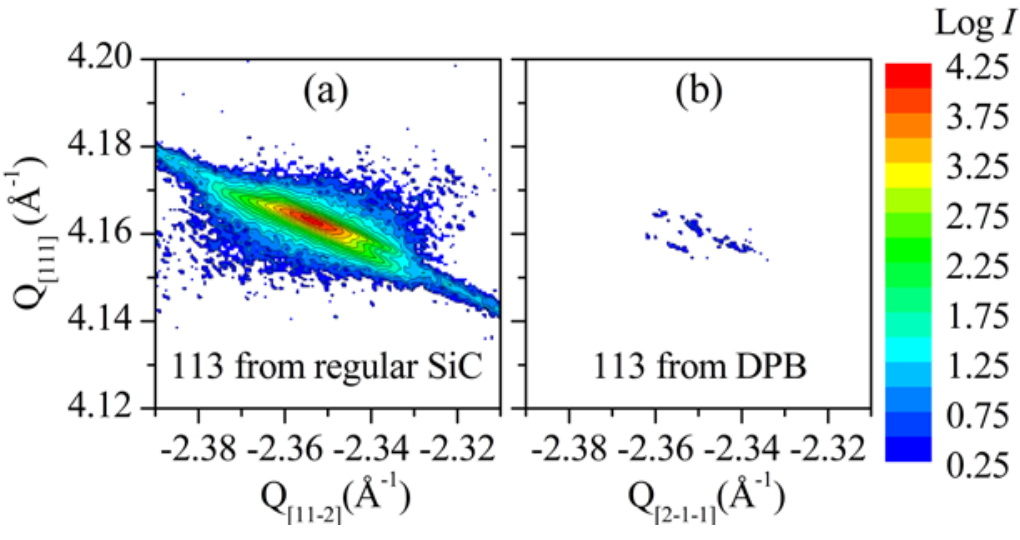

Fig.2 (a) RSM of the 113 diffraction peak for the $12.5 \mu \mathrm{m}$ thick $3 \mathrm{C}$ epilayer and b) after $60^{\circ}$ rotation of the crystal around its symmetry axis. the $(-111)$ plane whereas the streaks with an angle of $55^{\circ}$ are due to SFs lying in the (11-1) and (1-11) planes [22]. No symmetry around the [111] direction is observed in this case which further confirms the absence of DPB. Generally, the thicker the layer the more chance we have to obtain DPB-free layer, meaning that the lateral growth of one domain over the second one is dominant. However, thin layers with very low DPB density from microscopy pictures have also been obtained, as presented here. From 


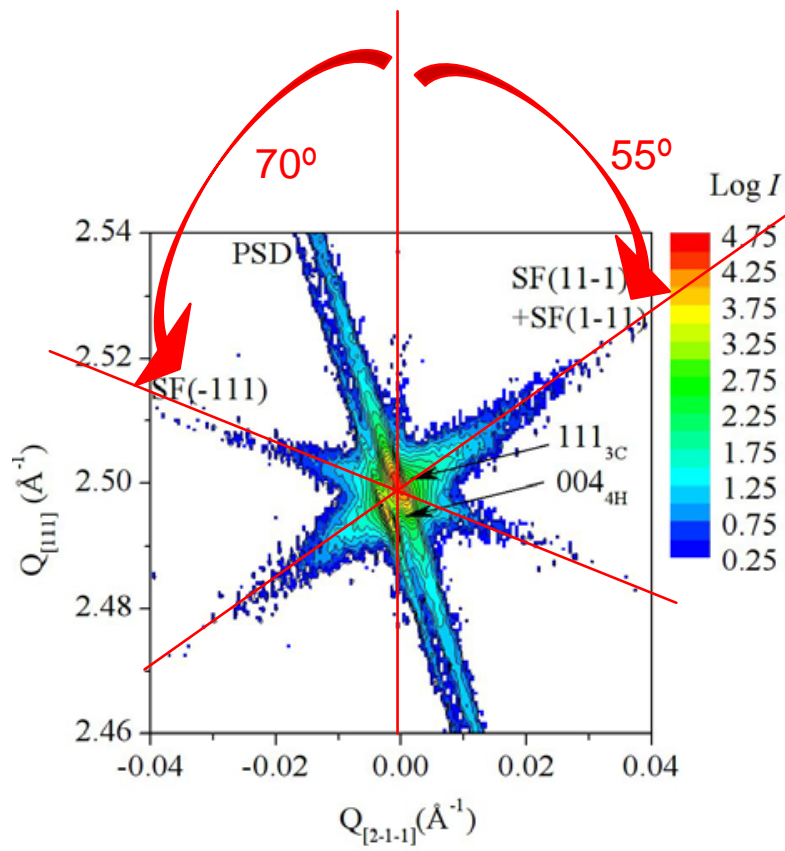

Fig.3 : RSM of the 111 Bragg peak for the same $12.5 \mu \mathrm{m}$ thick epilayer
XRD measurement [23] SF density has been found in the low $10^{4} \mathrm{~cm}^{-1}$. Investigations of a $35 \mu \mathrm{m}$ thick epilayers, have shown a narrow full-width at half-maximum of 16 arcsec for the (111) diffraction peak in a $2 \theta-\omega$ scan. This proves the high quality of the 3C-SiC epilayers. In addition high resolution XRD reveals that this single domain consists of slightly misoriented subdomains, which are the origin of the broadening of the $\omega$ scan peak (see Ref 24). These sub-domains are proposed to be domains existing or emerging between the SFs.

Photoluminescence (PL) experiments at $2 \mathrm{~K}$ have also been performed on many samples. Fig.4 shows a typical PL spectrum recorded for the 12.5 $\mu \mathrm{m}$ thick epilayers. The dominant feature is coming from the near band gap emission (NBG between $5200 \AA$ and $5500 \AA$ corresponding to 2.38-2.25 eV). The part around $5700 \AA$ is due to two phonons replica of the NBG emission. In addition the $D_{\text {I }}$ center is very weakly observed at $6287 \AA(1.97 \mathrm{eV})$. Feature from donor-acceptor transitions as broad band are never observed from our samples. The NBG emission is always dominated by the lines associated to the donor (nitrogen) bound excitons with no-phonon (noted $\mathrm{N}_{0}$ in Fig.4), phonon replica ( $\mathrm{N}_{\mathrm{TA}}, \mathrm{N}_{\mathrm{LA}}, \mathrm{N}_{\mathrm{TO}}$ and $\mathrm{N}_{\mathrm{LO}}$ ) and even multi bound exciton lines (not labeled in Fig.4) which are an indication of high purity material. The free-exciton can also be observed, however at slightly higher temperature than $2 \mathrm{~K}$. The full-width at half-maximum of the $\mathrm{N}_{\mathrm{TA}}$ line has been proposed to be a measure of the $\mathrm{N}$ content in 3C polytype [25]. For many of our

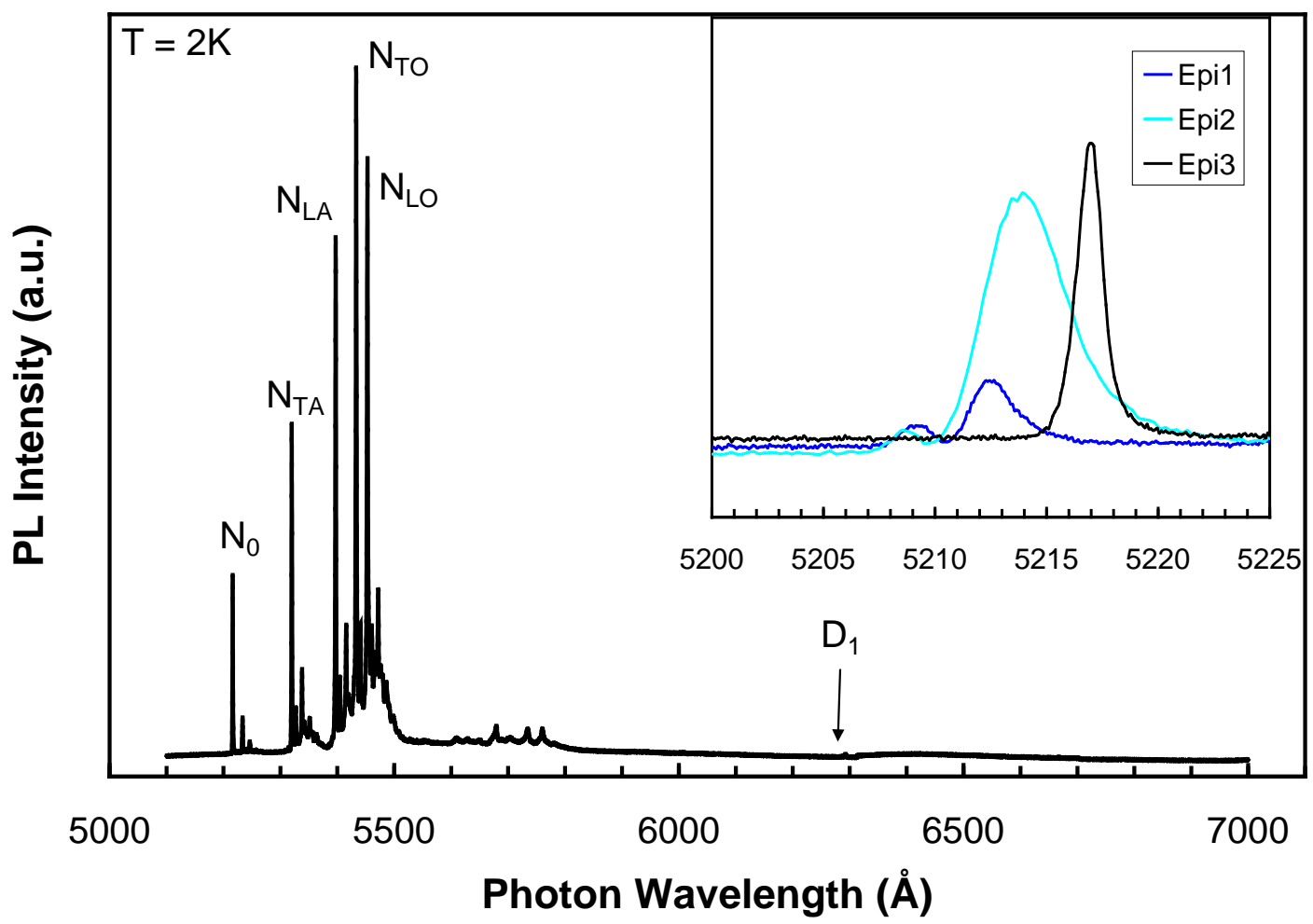

Fig. 4: Low temperature photoluminescence spectrum at $2 \mathrm{~K}$ of the $12.5 \mu \mathrm{m}$ thick $3 \mathrm{C}-\mathrm{SiC}$ epilayers. The inset shows the no-phonon line for three different layers. 
intentionally doped samples this width was about $1 \mathrm{meV}$ which should correspond to a concentration of $2 \times 10^{16} \mathrm{~cm}^{-3}$. Checking more carefully the width and the position of the lines, shift, broadening and splitting can also be observed as illustrated in the inset of Fig. 4 for three different epilayers. The $\mathrm{N}_{0}$ line for the sample called "Epi1" is slightly shifted from the expected line position but shows an extremely small width which corresponds to the limitation of the PL system. For the two others layers the $\mathrm{N}_{0}$ line is broad, slightly asymmetric and with a high energy component at 1.8 and $2.3 \mathrm{meV}$, respectively. This has probably been observed by other groups and can be seen from the published PL spectra, but has never been mentioned or commented to the best of our knowledge (a line called $\mathrm{B}_{0}$ has been reported [26], however it is located on the low energy side of the $\mathrm{N}$ bound exciton lines).

\section{Conclusions}

DPB-free 3C epilayers can be grown on nominally on-axis 4H-SiC substrate with CVD process which already has been recognized as the most advance technique for the growth of $4 \mathrm{H}$ on $4 \mathrm{H}$ substrates. Understanding the growth mechanism and particularly the elimination of DPB needs detailed structural studies. However epilayers thicker than $12 \mu \mathrm{m}$ have been grown for which at least $8 \mu \mathrm{m}$ consists of a single domain. Typical SF density is found in the low $10^{4} \mathrm{~cm}^{-1}$ range.

\section{Acknowledgments}

The Swedish Research Council (VR 2009-3383) and the Swedish Energy Agency (project 32917-1) are gratefully acknowledged for financial support.

\section{References}

[1] R. Cheung; "Silicon Carbide Micro Electromechanical Systems for Harsh Environments"; Imperial College Press, 2006

[2] J. Wan, M.A. Capano, M.R. Melloch, N-channel 3C-SiC MOSFETs on silicon substrate,_IEEE Electron Device Lett. 23 (2002) 482

[3] S.E. Saddow, A. Oliveros, C. Coletti, C.L. Frewin, N. Schettini, A. Oliveros and M. Jarosezeski, Single-Crystal Silicon Carbide: A Biocompatible and Hemocompatible Semiconductor for Advanced Biomedical Applications, Mat. Sci. For. 679-680 (2011) 824.

[4] Y. Okui, C. Jacob, S. Ohshima and S. Nishino, Control of Pendeo Epitaxial growth of 3C-SiC on Silicon Substrate, Mat. Sc. For. 433-436 (2003) 209.

[5] M. V. S. Chandrashekhar, C. I. Thomas, J. Lu, M. G. Spencer, Electronic properties of a 3C/4H SiC polytype heterojunction formed on the Si face, Appl. Phys. Lett. 90 (2007) 173509

[6] A. A. Lebedev, A. M. Strel'chuk, N. S. Savkina, E. V. Bogdanova, A. S. Tregubova, A. N. Kuznetsov, and L. M. Sorokin, Investigation of the $p^{-}-3 \mathrm{C}-\mathrm{SiC} / n^{+}-6 \mathrm{H}-\mathrm{SiC}$ heterostructures with modulated doping, Techn. Phys. Lett., 28 (2002) 1011.

[7] H.S. Kong, J.T. Glass and R.F. Davis, Growth rate, surface morphology, and defect microstructures of $\beta-\mathrm{SiC}$ films chemically vapor deposited on $6 \mathrm{H}-\mathrm{SiC}$ substrates , J. Mater. Res. 4 (1989) 204

[8] K. Nishino, T. Kimoto, H. Matsunami, Reduction of Double Positioning Twinning in 3C-SiC Grown on \alpha -SiC Substrates, Jpn. J. Appl. Phys. 36 (1997) 5202

[9] Z.Y. Xie, J.H. Edgar, B.K. Burkland, J.T. George, and J. Chaudhuri, DPBs-free and polytype

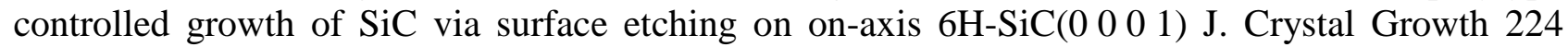
(2001) 235 
[10] M. Soueidan, G. Ferro, B. Nsouli, F. Cauwet, J. Dazord, G. Younes, and Y. Monteil, Effect of growth parameters on the heteroepitaxy of 3C-SiC on $6 \mathrm{H}-\mathrm{SiC}$ substrate by chemical vapor deposition, Mat. Sc. Eng. B 130 (2006) 66

[11] V. Jokubavicius, R. Liljedahl, Y. Ou, H. Ou, S. Kamiyama, R. Yakimova, and M. Syväjärvi, Geometrical Control of 3C and 6H-SiC Nucleation on Low Off-Axis Substrates, Mat. Sc. For 679680 (2011) 103

[12] M. Soueidan, G. Ferro, O. Kim-Hak, F. Cauwet, B. Nsouli, Vapor-Liquid-Solid Growth of 3C-SiC on $\alpha$-SiC Substrates. 1. Growth Mechanism, Cr. Gr Des. 8 (2008) 1044.

[13] L. Latu-Romain, D. Chaussende and M. Pons, High-Temperature Nucleation of Cubic Silicon Carbide on (0001) Hexagonal-SiC Nominal Surfaces, Cr. Gr. Des. 6 (2006) 2788.

[14] K. Seki, S. Harada and T. Ujihara, Solution growth of DPB-free 3C-SiC, this proceeding

[15] A. Fissel, Artificially layered heteropolytypic structures based on SiC polytypes: molecular beam epitaxy, characterization and properties, Phys. Rep. 379 (2003) 149

[16] M. Camarda, Monte Carlo study of hetero-polytypical growth of cubic on hexagonal silicon carbide polytypes, Surf. Sc 606 (2012) 1263

[17] A. J. Trunek, P. G. Neudeck, J. A. Powell and D. J. Spry, Comparative Growth Behavior of 3C-SiC Mesa Heterofilms with and without Extended Defects, Mat. Sc. For. 457-460 (2004) 261.

[18] A. Henry, S. Leone, F.C. Beyer, S. Andersson, O. Kordina and E. Janzén. Chloride based CVD of 3C-SiC on (0001) a-SiC Substrate, Mat. Sc. For. 679-680 (2011) 75.

[19] X. Li, S. Leone, S. Andersson, O. Kordina, A. Henry and E. Janzén, CVD Heteroepitaxial Growth of 3C-SiC on 4H-SiC (0001) Substrates, Mat. Sc. For. 717-720 (2012) 189

[20] D. Chaussende, P. Chaudouet, L. Auray, M. Pons and R. Madar, Electron Back Scattering Diffraction (EBSD) as a tool for the investigation of 3C-SiC nucleation and growth on $6 \mathrm{H}$ or $4 \mathrm{H}$, Mat. Sc. For, 457-460 (2003) 387

[21] M. Marinova, A. Mantzari, and E.K. Polychroniadis, Some recent results on the 3C-SiC structural defects, Nano. Mat., Thin Films and Hard Coatings for Advanced Applications 159 (2010) 39

[22] A. Boulle, D. Chaussende, F. Conchon, G. Ferro and O. Masson, Characterization of stacking faults in thick 3C-SiC crystal using high-resolution diffuse X-ray scattering, J. Crys. Gr. 310 (2008) 982

[23] A. Boulle, D. Chaussende, L. Latu-Romain, F. Conchon, O. Masson, and R. Guinebretière, Xray diffuse scattering from stacking faults in thick $3 C$-SiC single crystals, Appl. Phys. Lett. 89 (2006) 091902

[24] H. Jacobson, X. Li, E. Janzén, A. Henry, Structural investigation of heteroepitaxial 3C-SiC grown on $4 \mathrm{H}-\mathrm{SiC}$ substrates, this proceeding.

[25] J. Camassel, S. Juillaguet, M. Zielinski, and C. Balloud, Application of LTPL Investigation Methods to CVD-Grown SiC, Chem. Vap. Dep. 12 (2006) 549

[26] W.J. Choyke, Z.C. Feng and J.A. Powell, Low-temperature photoluminescence studies of chemical-vapor-deposition-grown 3C-SiC on Si, J. Appl. Phys. 64 (1988) 3163. 